As the Nation's principal conservation agency, the Department of the Interior has responsibility for most of our nationally owned public lands and natural resources. This includes fostering the wisest use of our land and water resources, protecting our fish and wildlife, preserving the environmental and cultural values of our national parks and historical places, and providing for the enjoyment of life through outdoor recreation. The Department assesses our energy and mineral resources and works to assure that their development is in the best interests of all our people. The Department also has a major responsibility for American Indian reservation communities and for people who live in Island Territories under U.S. administration.

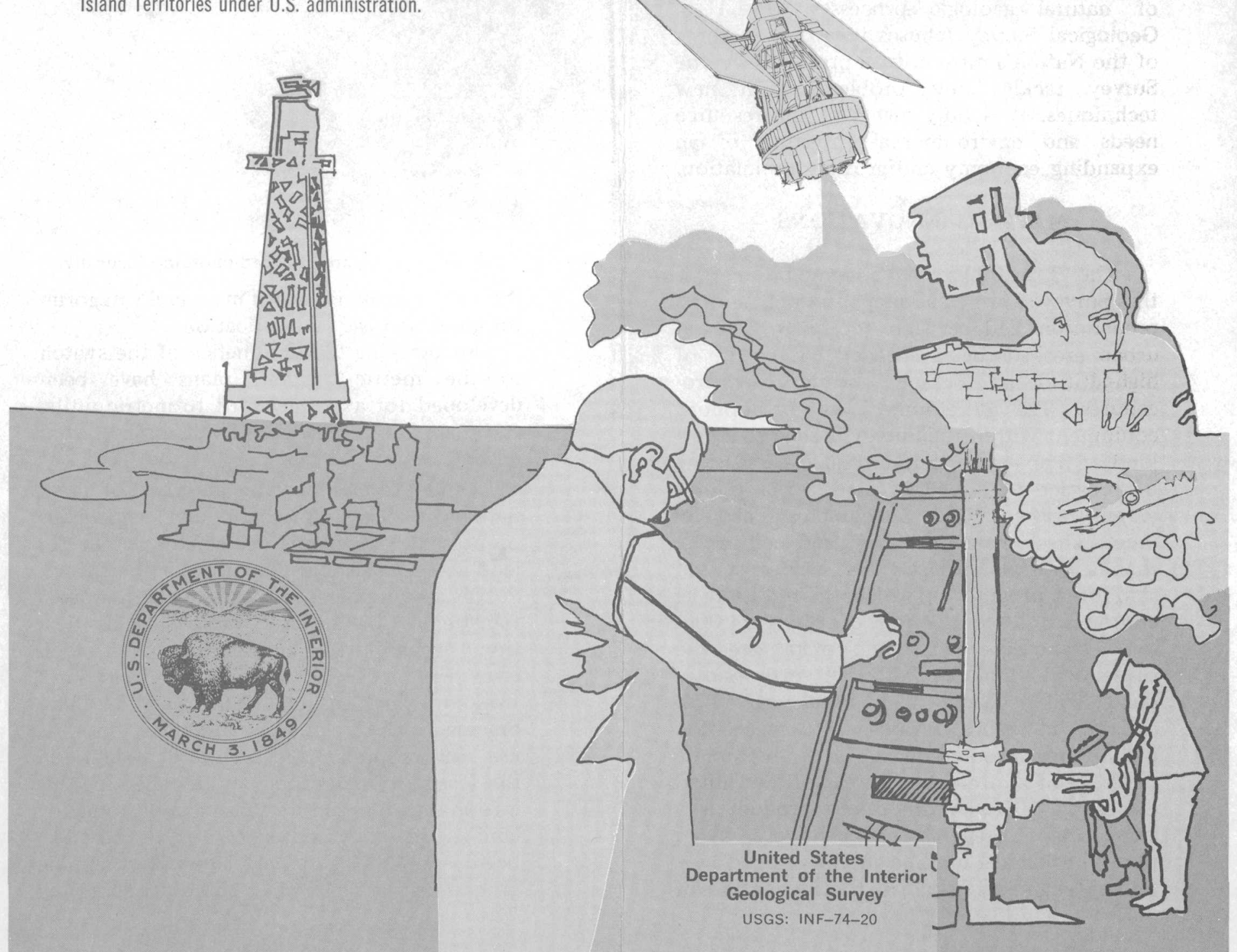

\title{
NEW ACTIVITIES AT THE U.S. GEOLOGICAL SURVEY
}




\section{NEW ACTIVITIES}

\section{AT THE}

\section{U. S. GEOLOGICAL SURVEY}

As the Nation's principal source of information about the configuration of the land surface, the composition and structure of the rocks at and beneath the surface, the distribution and character of its energy, mineral, and water resources, and the nature of natural geologic processes, the U.S. Geological Survey focuses its work on some of the Nation's most critical problems. As the Survey tackles new problems with new techniques, it is fully aware of the resource needs and environmental pressures of an expanding economy and growing population.

\section{MAPPING INNOVATIONS}

The 1:24,000-scale topographic map is the Survey's principal map product, and its preparation and revision (every 5 years in urban areas) is being speeded by the use of high-altitude photography and improved procedures. The development of orthophoto equipment within the Survey has led to a new kind of map - an orthophotoquad-consisting of mosaics of scale-corrected aerial photographs with limited cartographic enhancement. These maps are being produced in less than a year at the $1: 24,000$ scale as a first step of a program in which the addition of contours and completion of the 1:24,000scale standard topographic maps are the subsequent steps. Some 1,500 orthophotoquads will be produced in fiscal year 1974, and it is being proposed to accelerate orthophoto production so as to complete coverage of all unmapped areas of the United States by 1978. Another new product is a slope map, prepared inexpensively by a photomechanical method just developed by a Survey engineer, in which the inclination of

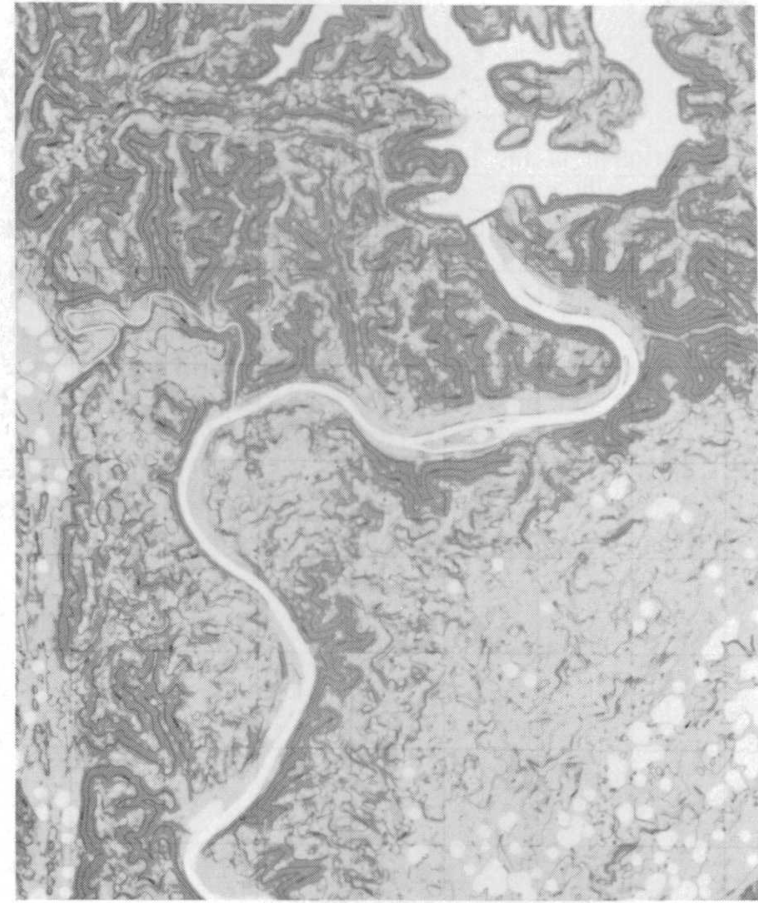

Part of a slope map produced photomechanically.

the land surface is shown in several categories for quick and easy identification.

Recognizing the imminence of the switch to the metric system, plans have been developed for a gradual shift to metric units, and mapping in metric units has been started in some areas.

Land use has become an issue of great national concern. And, of course, knowledge of present land use is the starting point for land-use analysis and planning for the future. Survey geographers have recently developed a four-tiered, hierarchical land-use classification, providing for increased detail in each level from I to IV of the tier, and have worked with other Federal and State organizations to achieve standardization in its use. Several pilot projects have demonstrated the feasibility and efficiency of collecting this information by remote sensing and producing land-use maps by computer. It is proposed to begin now a national land-use mapping program at a scale of $1: 250,000$, achieving 
complete coverage by 1978 . Standard topographic maps contain several categories of land use, and the Survey is experimenting with the addition of other categories to make land-use maps at the 1:24,000 scale a part of the regular mapping process.

For some years the Geological Survey has been delineating the Nation's flood-prone lands. This program has recently been accelerated by financial assistance from the Department of Housing and Urban Development (HUD) because the information is essential for management of the Federal Flood Insurance Program and for wise land-use planning.

\section{REMOTE EARTH RESOURCES STUDIES}

Under the Earth Resources Observation Systems (EROS) Program, the Survey makes imagery available to the public from the National Aeronautics and Space Administration (NASA) Aircraft Program, Earth Resources Technology Satellite (ERTS), and Skylab, and applications for use of these data are being developed. The ERTS imagery is obtained in several spectral bands from which the data may be used alone or in combination. False-color imagery enhances the identification of special features such as vegetation in vigorous growth, water, and certain kinds of pollution. Each ERTS image represents a synoptic view of 13,225 square miles, and this bird's-eye view permits recognition of some large geologic features not previously recognized on the ground or on low-altitude photography. The satellite repeats each orbit every 18 days, and repetitive coverage makes it possible to monitor crop production, rangeland conditions, snow cover, floods, and many other dynamic phenomena. Ground data-collection platforms which provide for frequent transmission of hydrologic, seismic, and volcanologic data through the satellite to ground data- acquisition stations are also in experimental operation.

Also in cooperation with NASA there have been diverse activities in planetary exploration, including the geologic mapping of the Moon and Mars, training of the astronauts, and study of lunar samples. Developing knowledge of the structure, composition, and origin of the Moon is helping to cast light on the history and origin of the Earth-knowledge that may have applications to such practical problems as mineral exploration.

\section{MINERALS}

Geologic mapping and energy and mineral resource studies continue to assist in planning for exploration and in evaluating the Nation's resource potential. Now in operation, although not yet complete, is a computerized resource data information bank which will not only help in national resource appraisal but will also provide data on mineral distribution that will assist in exploration.

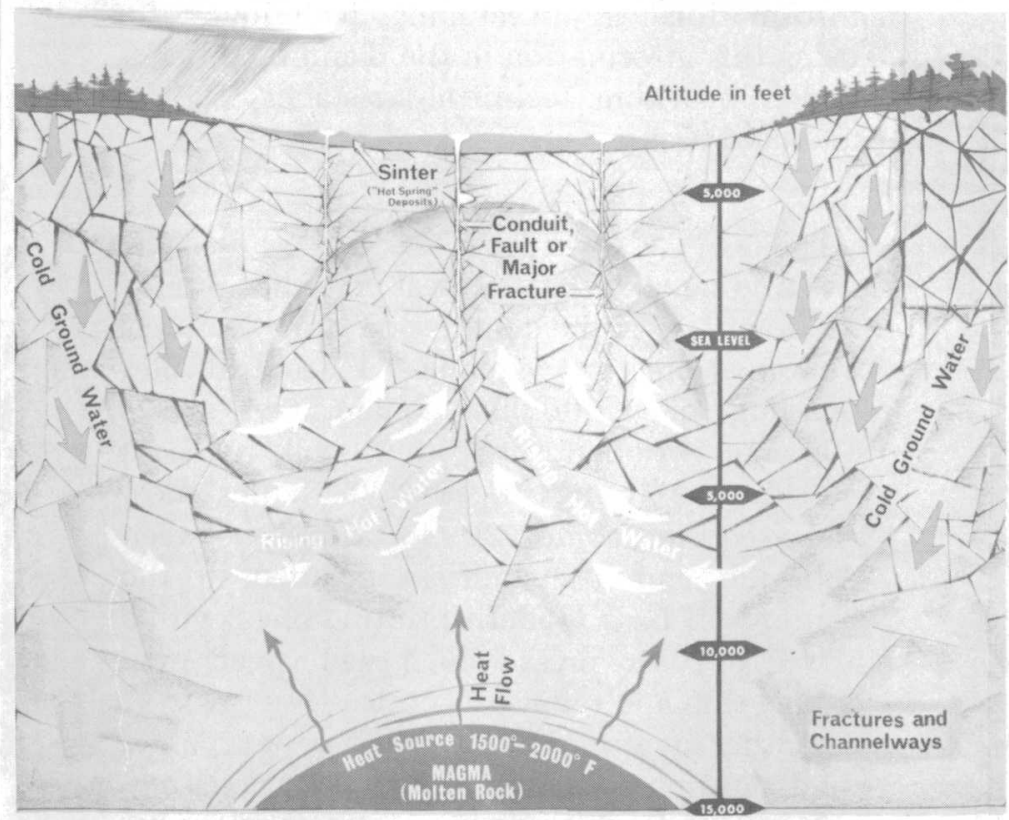

Cross section of a typical geothermal area. 
An oil platform in the Gulf of Mexico, under supervision of the Geological Survey.

Rapidly expanding since the passage of the Geothermal Steam Act in 1970 has been research on geothermal energy, aimed primarily at learning how to find and evaluate concealed geothermal reservoirs, to appraise the Nation's geothermal resource potential, and to determine what may be the environmental effects of production of geothermal energy.

The Geological Survey does not issue mineral leases on Federal land (that is the responsibility of the Bureau of Land Management), but the Survey is charged with the supervision of operations authorized by leases. It is in this area where much of the new action is and where some of the greatest challenges lie. The Survey is confronted with the real world problems of extracting needed minerals in an environmentally safe and acceptable fashion. On the Outer Continental Shelf, where there are now some 2,000 petroleum production platforms and more than 10,000 producing wells, the Survey has recently strengthened regulations and instituted an inspection system to reduce the danger of oil spills and other accidents. Onshore, where some 12,000 producing leases are supervised and the production of western coal is rapidly expanding, requirements and procedures are being developed that should make operations on Federal and Indian lands exemplary in their treatment of environmental problems.

\section{WATER ACTIVITIES}

Water resources are one of the most critical and sensitive parts of the environment, and to monitor water quality effectively a National Stream Quality Accounting Network is being developed. When completed, this network of 525 stations will provide baseline data on approximately 60 physical, chemical, and biological variables. By mid 1974, about 20 percent of the network will be in operation.

Collection of data on surface and ground water continues to be a fundamental part of the Survey's activity but, increasingly, the emphasis in water resource studies is passing from the mere presentation of data in a passive mode to the modeling of the dynamic system. This not only brings about new understanding of the movement of surface and ground water, but permits prediction and analysis of the impact of alternative proposals for development and management. 


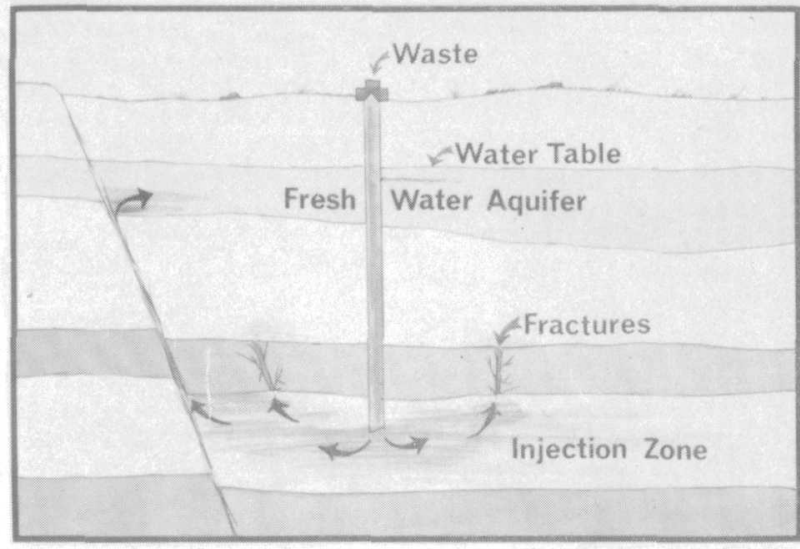

Waste injection well.

Also new in the water program is research on the use of underground space, both for the storage of waste and for the temporary storage of fresh water, natural gas, and other benign fluids. Underground space, in the form of pore and fracture space within the rocks, is a newly recognized resource of vast dimensions - possibly some 125,000 cubic miles in the upper $21 / 2$ miles of the Earth's crust within the United States - and one that is either renewable or nonrenewable depending on how it is used.

\section{NATURAL HAZARDS RESEARCH}

Contributing to the reduction of damage from natural hazards is much research related to volcanic eruptions, mudflows, landslides, and earthquakes. The Earthquake Hazards Reduction Program aims not only at identification of areas of high risk, but also at acquiring the ability to predict the time and intensity of earthquakes and to control them through the gradual release of strain. The possibilities here - and the problems - are tremendous, but progress is being made in all phases of the program. Ability in this area has been much expanded by the recent transfer of the National Oceanic and Atmospheric Administration (NOAA) earthquake research and seismological network to the Survey and by a substantial budget increase in fiscal year 1973.

\section{INFORMATION}

Recently, it has been realized that much information given in maps and technical publications is understandable only to scientists and engineers and that the policymakers and planners who need the information have not been getting it in a usable form. Also, many of today's environmental, land-use, and resource problems are highly complex in nature and require multidisciplinary data for their solution.

Recognizing these problems, the Survey has begun to place much emphasis on means of assembling complex data, translating and communicating them to users, and making them more readily accessible to those who need resource and land information as the basis for intelligent action. Much of this effort has been experimental or exploratory, but has already been fruitful. In an Urban Area Studies program, partly supported by HUD, and a Land Resource Analysis program, for example, multidisciplinary folios have been prepared which contain maps and other information aimed at user problems and translated into terms users can understand. In the two dozen or so areas where such studies have been undertaken, they have been

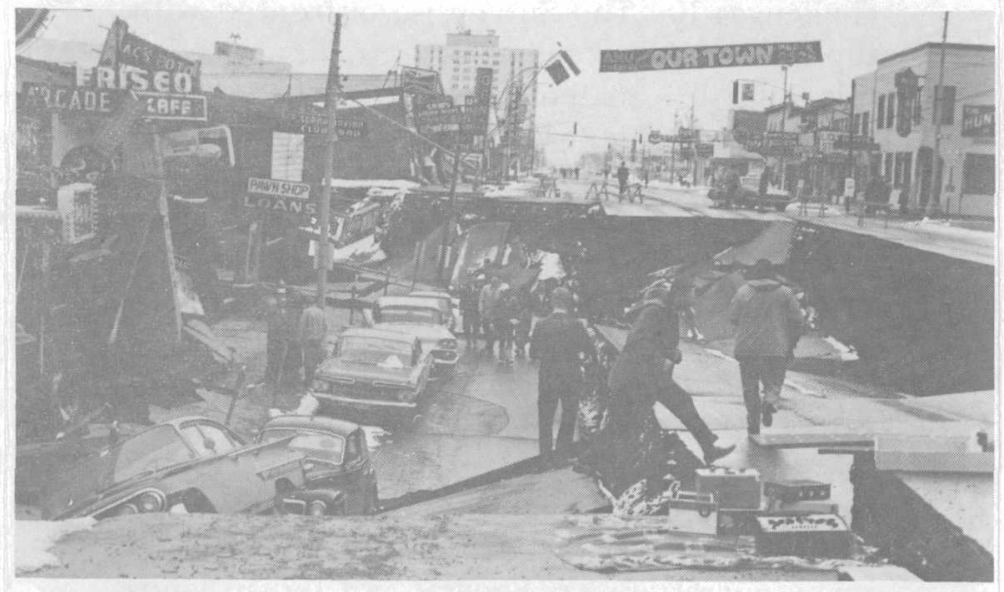

Collapse of city streets in Anchorage, Alaska, caused by a landslide following the 1964 earthquake. 
received with enthusiasm by planners and local civic officials.

In a Resource and Land Information (RALI) Program - an Interior Department program in which the Survey is the lead Bureau-work has been focused on developing ways of making information more readily available to the public. One of the major parts of the RALI Program is the development of a catalog or directory to Interior Department resource and land information. This catalog will be usable with the discipline-oriented bases in the Department such as the National Water Data Exchange, the National Cartographic Information Center, and the Computerized Resource Information Bank. It will enable a planner to find the variety of information he needs to solve a particular problem. This information ranges from the topographic, geologic, and hydrologic data of the Geological Survey to those on fish and wildlife, recreation, mining, rangeland, and so on from other Interior Bureaus. The Survey is also working closely with various States in identifying needs for resource and land information, in developing techniques for using this information in the planning process, and in providing technical assistance to State and land-user groups.

\section{THE FUTURE}

Adding to the interest at the Survey headquarters is the completion of its National Center at Reston, Virginia - a beautiful new building of 1,000,000 square feet, on a 105-acre wooded site, that will make it possible to bring together activities now scattered in some 30 locations between Beltsville and Alexandria. Included in the Center will be a modern printing plant with a new five-color press which will speed map publication and reduce its cost.

Other new facilities consist of a separate solid state physics laboratory under construction on the Reston campus, a special mapping facility nearby, the EROS Data Center at Sioux Falls, South Dakota, and the Gulf Coast Hydroscience Center at the Mississippi Test Facility.

Looking ahead, the sense of urgency in the mission of the Survey and other earth scientists and engineers deepens. There is the need to build a "Second" America between now and the end of the century. In that period, it will be necessary for Americans to produce, manufacture, and build as much as they have throughout the history of the Nation, even if during that period it is possible to reduce the rate of economic and population growth. And because these are the elements which lead to environmental deterioration, the Nation may incur as much environmental damage again as was inflicted in building the "First" America - unless actions are taken to avoid it. Sound information about the land and its resources is essential to success in both aspects of the problem, and the Geological Survey is keenly aware of the accelerating effort which will be required of it.

by Dr. V. E. McKelvey

Director, U. S. Geological Survey

Reprinted from THE MILITARY ENGINEER for January-February, 1974

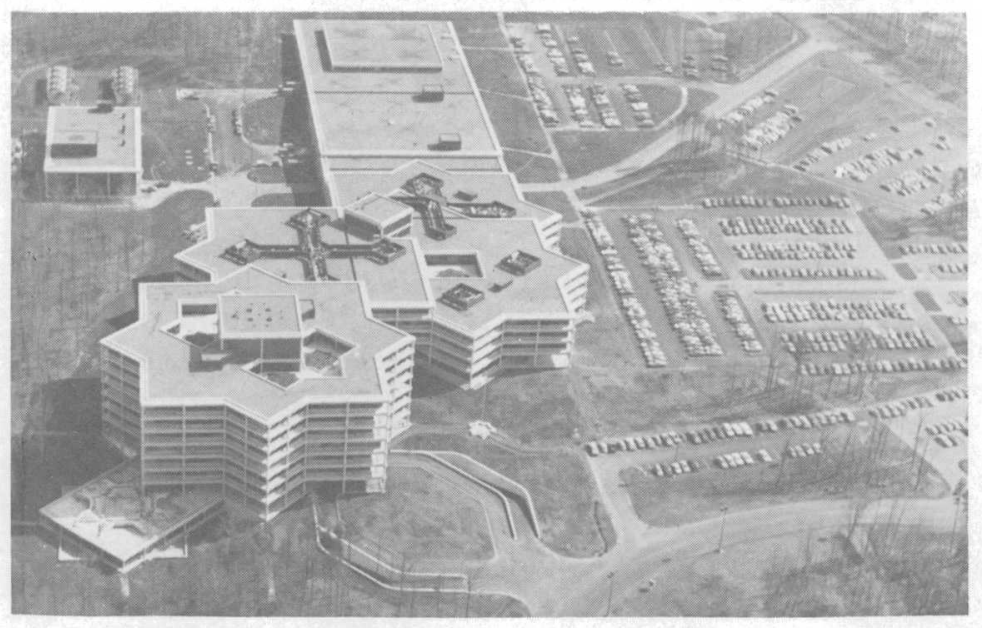

U. S. Geological Survey National Center, Reston, Virginia. 